\title{
The reaction norm of Augustine and Moldova grape varieties in the agroecological conditions of the moderate continental climate of the south of Russia
}

\author{
Valeriy Petrov*, Dmitriy Russo, Aleksandr Krasilnikov, and Anna Marmorshtein
}

Federal State Budget Scientific Institution «North Caucasian Federal Scientific Center of Horticulture, Viticulture, Wine-making», str. 40 Let Pobedy, 39, Krasnodar, 350901, Russia

\begin{abstract}
The grape plant reacts by modification variability of phenotypic traits to the variation of weather conditions. The reaction of the Augustine and Moldova grape varieties to the variability of natural conditions was ambiguous. In the Augustine, the lower limit of the modification variability of the cluster mass is 354 and the upper limit is $410 \mathrm{~g}$, the grape yield is 8.1 and $11.5 \mathrm{~kg} / \mathrm{bush}$, the sugar content of the berry juice is 15.8 and $17.5 \mathrm{~g} / 100$ $\mathrm{cm}^{3}$, in the Moldova, respectively, 387 and $457 \mathrm{~g}, 9.6$ and $13.2 \mathrm{~kg} / \mathrm{bush}, 16.4$ and $17.8 \mathrm{~g} / 100 \mathrm{~cm}^{3}$. The reaction norm of the Augustine according to the phenotypic traits is following: the cluster mass is $56 \mathrm{~g}$, the yield is 3.4 $\mathrm{kg} / \mathrm{bush}$ and the sugar content is $1.7 \mathrm{~g} / 100 \mathrm{~cm}^{3}$, of the Moldova, respectively, 70, 3.6 and 1.4. Against the background of the application of fertilizers, the lower and upper limits of variability have increased as well as the reaction norm by cluster mass and yield, however reaction norm by sugar content decreased.
\end{abstract}

\section{Introduction}

The grape plant has a high plasticity in the conditions of the display of natural biotic and abiotic stressors. This biological character allows the plant to grow and bear fruit effectively in conditions of a lack of mineral nutrition and precipitation, to tolerate high maximum and low minimum air temperatures [1-6]. At the same time, grape plants respond positively to optimal environmental conditions [7-11]. Under the influence of changes in the habitat, as well as anthropogenic factors, grape plants react to the variability of phenotypic traits [1217]. The modification variability can vary in a wide range and is expressed by the reaction norm. The reaction norm of table varieties, expressed by the indicators of the cluster mass, productivity and sugar content of berry juice, is of great scientific and practical importance for the creation of new varieties and the development of variety-oriented agricultural technologies for functionally directed grape cultivation.

The purpose of these studies is to establish the limits of the modification variability of the cluster mass, the yield and the sugar content of the berry juice of widely used grape varieties

\footnotetext{
* Corresponding author: petrov 53@mail.ru
} 
in the agroecological conditions of the south of Russia. These studies were done for the first time.

\section{Materials and methods}

The introduced table grape varieties Augustine and Moldova were used as the object of research. The subject of research is the phenotypic reaction of grapes to unstable weather conditions and the nonroot application of AgroMaster and Lignohumate fertilizers.

The research was carried out using modern methods of field studies. Agrobiological records of plantings productivity and grape quality were carried out using methods of agrotechnical study of grape varieties and technologies.

The research was carried out in the conditions of the Black Sea agroecological zone of viticulture in the Krasnodar region on the Taman Peninsula, the Progress village. The climate at the research area is moderately continental. The annual average air temperature is $11.8^{\circ} \mathrm{C}$, during the growing season (May - September) $-20.8^{\circ} \mathrm{C}$, the maximum rises to plus $38.0^{\circ} \mathrm{C}$, the minimum during the wintering period of grapes falls to minus $24^{\circ} \mathrm{C}$. The annual amount of atmospheric precipitation is $526 \mathrm{~mm}$, during the growing season $-209 \mathrm{~mm}$, during the active growth of grape berries (II. June-III. august) $-161 \mathrm{~mm}$. The soil is southern chernozem.

\section{Results and discussion}

During the research period, the average annual air temperature at the research area varied from 12.6 to $13.4{ }^{\circ} \mathrm{C}$ and was higher than the average annual norm by $0.8-1.6^{\circ} \mathrm{C}$, during the growing season - from 21.5 to $22.5^{\circ} \mathrm{C}$, which is higher than the norm by $0.7-1.7^{\circ} \mathrm{C}$, during the active growth of grapes - from 23.7 to $24.7^{\circ} \mathrm{C}$, higher than the norm by $0.8-1.8^{\circ} \mathrm{C}$. The maximum temperature during the growing season was below the norm by $2.0-4.0^{\circ} \mathrm{C}$, the minimum during the period of active growth of grapes exceeded the norm by $1.0-5.0{ }^{\circ} \mathrm{C}$. Atmospheric precipitation varied in a wide range. The highest annual atmospheric precipitation reached $636 \mathrm{~mm}$, the lowest $394 \mathrm{~mm}$, which is respectively $21 \%$ more and 25 $\%$ less than norm. During the period of active growth of grape berries, the largest amount of atmospheric precipitation exceeded the norm by $49 \%$, the lowest was below the norm by 67 $\%$. In general, the research area has unstable weather conditions and there is a tendency of climate warming (Table 1).

Table 1. Meteorological conditions at the research area

\begin{tabular}{|c|c|c|c|c|c|c|c|c|c|}
\hline \multirow{3}{*}{ Years } & \multicolumn{6}{|c|}{ Air temperature, ${ }^{\circ} \mathrm{C}$} & \multirow{2}{*}{\multicolumn{3}{|c|}{$\begin{array}{c}\text { Atmospheric } \\
\text { precipitation, mm }\end{array}$}} \\
\hline & \multicolumn{3}{|c|}{ Average } & $\max$ & \multicolumn{2}{|c|}{$\min$} & & & \\
\hline & $\begin{array}{l}\text { In a } \\
\text { year }\end{array}$ & $\begin{array}{c}\text { may- } \\
\text { september }\end{array}$ & $\begin{array}{l}\text { II.june- } \\
\text { III.august }\end{array}$ & $\begin{array}{c}\text { may- } \\
\text { september }\end{array}$ & $\begin{array}{l}\text { june- } \\
\text { august }\end{array}$ & $\begin{array}{l}\text { january- } \\
\text { march }\end{array}$ & $\begin{array}{l}\text { In a } \\
\text { year }\end{array}$ & $\begin{array}{c}\text { may- } \\
\text { september }\end{array}$ & $\begin{array}{l}\text { II.june- } \\
\text { III.august }\end{array}$ \\
\hline 2016 & 12.6 & 21.9 & 24.7 & 36.0 & 10.0 & -14 & 636 & 308 & 42 \\
\hline 2017 & 12.8 & 21.5 & 23.7 & 36.0 & 11.0 & -15 & 503 & 152 & 77 \\
\hline 2018 & 13.0 & 22.5 & 24.5 & 34.0 & 12.0 & -8 & 453 & 135 & 36 \\
\hline 2019 & 13.2 & 21.7 & 23.8 & 34.0 & 14.0 & -6 & 394 & 134 & 67 \\
\hline 2020 & 13.4 & 21.8 & 23.9 & 36.0 & 12.0 & -11 & 415 & 228 & 161 \\
\hline $\begin{array}{l}\text { long- } \\
\text { term } \\
\text { annual } \\
\text { average }\end{array}$ & 11.8 & 20.8 & 22.9 & 38.0 & 9.0 & -24 & 526 & 209 & 108 \\
\hline
\end{tabular}


The reaction of the studied grape plants to the variability of natural conditions during the growing period was ambiguous in terms of phenotypic characteristics. The modification variability of phenotypic traits was most strongly influenced by the temperature regime and precipitation in general for the year, as well as during the period of active growth of grapes. According to Table 2, the correlation dependence of the average cluster mass and the yield on the average annual air temperature and atmospheric precipitation during the period of berry growth was mainly medium and strong, especially in the Moldova variety. The sugar content of the berry juice was strongly dependent.

Table 2. Correlation dependence of the grape phenotypic characteristics on the weather

\begin{tabular}{|c|c|c|c|c|c|c|}
\hline \multirow[b]{2}{*}{ Phenotypic traits } & \multicolumn{3}{|c|}{ Average air temperature, ${ }^{\circ} \mathrm{C}$} & \multicolumn{3}{|c|}{ Atmospheric precipitation, $\mathrm{mm}$} \\
\hline & $\begin{array}{l}\text { In a } \\
\text { year }\end{array}$ & \begin{tabular}{c|} 
may- \\
september
\end{tabular} & $\begin{array}{c}\text { II.june- } \\
\text { III.august }\end{array}$ & \begin{tabular}{|c|} 
In a \\
year
\end{tabular} & $\begin{array}{c}\text { may- } \\
\text { september }\end{array}$ & $\begin{array}{c}\text { II.june- } \\
\text { III.august }\end{array}$ \\
\hline \multicolumn{7}{|c|}{ Augustine without fertilizers } \\
\hline Average cluster mass, $\mathrm{g}$ & -0.72 & -0.37 & -0.09 & 0.41 & -0.21 & -0.67 \\
\hline Yield, kg/bush & 0.33 & -0.11 & -0.49 & -0.35 & -0.32 & 0.57 \\
\hline Sugar content, g/100 $\mathrm{cm}^{3}$ & 0.81 & 0.26 & -0.24 & -0.64 & -0.16 & 0.75 \\
\hline \multicolumn{7}{|c|}{ Augustine on the background of fertilizers } \\
\hline Average cluster mass, $\mathrm{g}$ & -0.49 & -0.84 & -0.43 & 0.35 & 0.04 & -0.24 \\
\hline Yield, kg/bush & 0.73 & -0.52 & -0.90 & -0.71 & -0.39 & 0.83 \\
\hline Sugar content, $\mathrm{g} / 100 \mathrm{~cm}^{3}$ & 0.87 & -0.28 & -0.79 & -0.84 & -0.46 & 0.82 \\
\hline \multicolumn{7}{|c|}{ Moldova without fertilizers } \\
\hline Average cluster mass, $\mathrm{g}$ & -0.69 & -0.07 & 0.25 & 0.44 & -0.08 & -0.86 \\
\hline Yield, kg/bush & 0.89 & -0.30 & -0.83 & -0.89 & -0.51 & 0.78 \\
\hline Sugar content, g/100 $\mathrm{cm}^{3}$ & 0.86 & -0.03 & -0.44 & -0.65 & -0.10 & 0.91 \\
\hline \multicolumn{7}{|c|}{ Moldova on the background of fertilizers } \\
\hline Average cluster mass, $\mathrm{g}$ & -0.74 & -0.12 & 0.07 & 0.39 & -0.28 & -0.82 \\
\hline Yield, kg/bush & 0.83 & -0.19 & -0.58 & -0.65 & -0.14 & 0.94 \\
\hline Sugar content, $\mathrm{g} / 100 \mathrm{~cm}^{3}$ & 0.71 & -0.05 & -0.63 & -0.73 & -0.52 & 0.69 \\
\hline
\end{tabular}

The cluster mass under the influence of unstable weather conditions varied of the Augustine variety from $354 \mathrm{~g}$ to $410 \mathrm{~g}$, of the Moldova variety from $387 \mathrm{~g}$ to $457 \mathrm{~g}$. The difference between the lower and upper thresholds of modification variability reached $16 \%$ and $18 \%$, respectively. Against the background of the fertilizers application, the cluster mass was higher than without fertilizers, but the range of variation was close to the variant without fertilizers. In the Augustine variety, the cluster mass varied from $424 \mathrm{~g}$ to $482 \mathrm{~g}$, in the Moldova variety from $421 \mathrm{~g}$ to $498 \mathrm{~g}$. The difference between the lower and upper thresholds of modification variability reached $14 \%$ and $18 \%$, respectively. The reaction norm to changes in weather conditions in the Augustine variety was equal to $56 \mathrm{~g}$ and in the Moldova variety to $70 \mathrm{~g}$, against the background of the use of fertilizers, the reaction rate increased and was equal to $58 \mathrm{~g}$ and $77 \mathrm{~g}$, respectively (Fig. 1). 

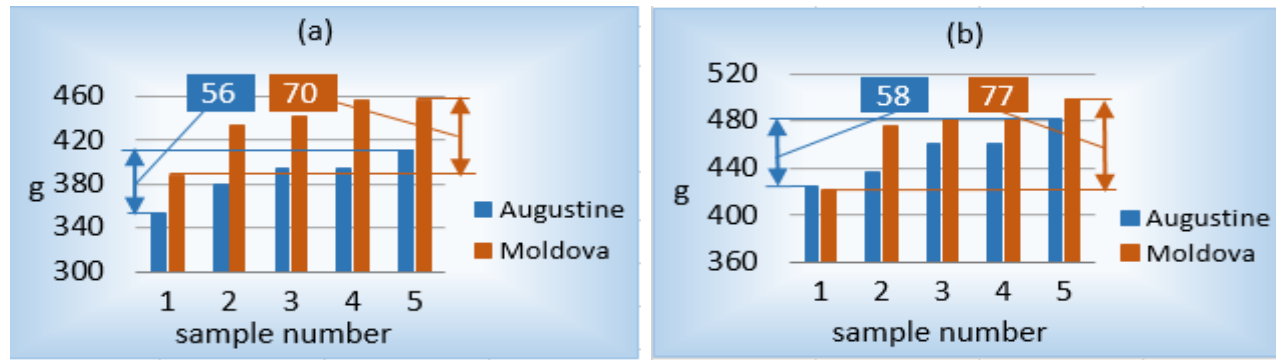

Fig. 1. The reaction norm of the grape cluster mass to natural conditions without the application of fertilizers (a) and against the background of the application of fertilizers (b)

The grape yield under the influence of changes in weather conditions of the Augustine variety varied from $8.1 \mathrm{~kg} / \mathrm{bush}$ to $11.5 \mathrm{~kg} / \mathrm{bush}$ (the difference between the lower and upper thresholds was $42 \%$ ), of the Moldova variety from $9.6 \mathrm{~kg} / \mathrm{bush}$ to $13.2 \mathrm{~kg} / \mathrm{bush}(38 \%)$, against the background of the application of fertilizers, respectively, from $10.6 \mathrm{~kg} / \mathrm{bush}$ to $17.9 \mathrm{~kg} /$ bush $(69 \%)$ and from $11.9 \mathrm{~kg} /$ bush to $18.1 \mathrm{~kg} / \mathrm{bush}(52 \%)$. The reaction norm to changes in weather conditions was $3.4 \mathrm{~kg} / \mathrm{bush}$ of the Augustine variety, $3.6 \mathrm{~kg} / \mathrm{bush}$ of the Moldova variety, and increased to $7.3 \mathrm{~kg} / \mathrm{bush}$ and $6.2 \mathrm{~kg} / \mathrm{bush}$, respectively, against the background of the application of fertilizers (Figure 2).
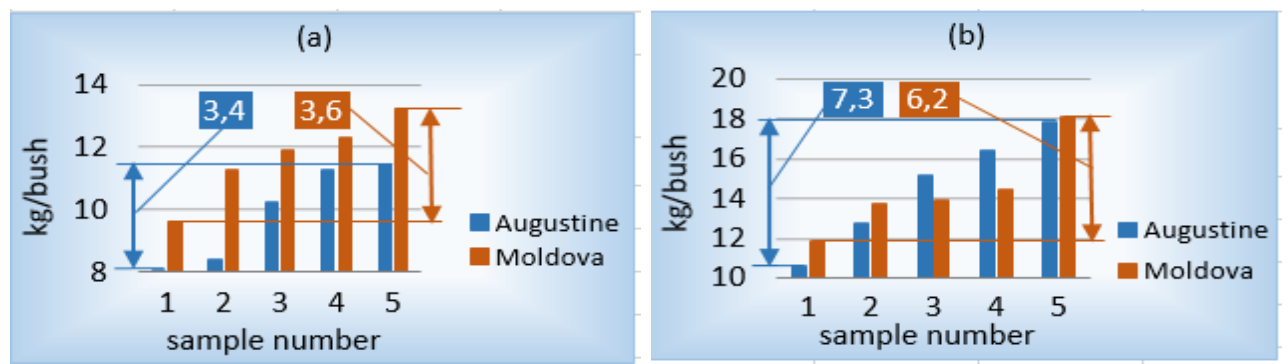

Fig. 2. The reaction norm of the grape yield to natural conditions without the application of fertilizers (a) and against the background of the application of fertilizers (b)

The sugar content of grape juice of the Augustine variety varied from $15.8 \mathrm{~g} / 100 \mathrm{~cm}^{3}$ to $17.5 \mathrm{~g} / 100 \mathrm{~cm}^{3}(11 \%)$, of the Moldova variety from $16.4 \mathrm{~g} / 100 \mathrm{~cm}^{3}$ to $17.8 \mathrm{~g} / 100 \mathrm{~cm}^{3}(8 \%)$, against the background of the application of fertilizers, respectively, from $18.3 \mathrm{~g} / 100 \mathrm{~cm}^{3}$ to $19.4 \mathrm{~g} / 100 \mathrm{~cm}^{3}(6 \%)$ and from $18.1 \mathrm{~g} / 100 \mathrm{~cm}^{3}$ to $19.4 \mathrm{~g} / 100 \mathrm{~cm}^{3}(7 \%)$. The reaction norm was equal in the Augustine variety to $1.7 \mathrm{~g} / 100 \mathrm{~cm}^{3}$ and in the Moldova variety to $1.4 \mathrm{~g} / 100$ $\mathrm{cm}^{3}$, against the background of the application of fertilizers, it decreased to $1.1 \mathrm{~g} / 100 \mathrm{~cm}^{3}$ and $1.3 \mathrm{~g} / 100 \mathrm{~cm}$ cubic, respectively (Figure 3 ).
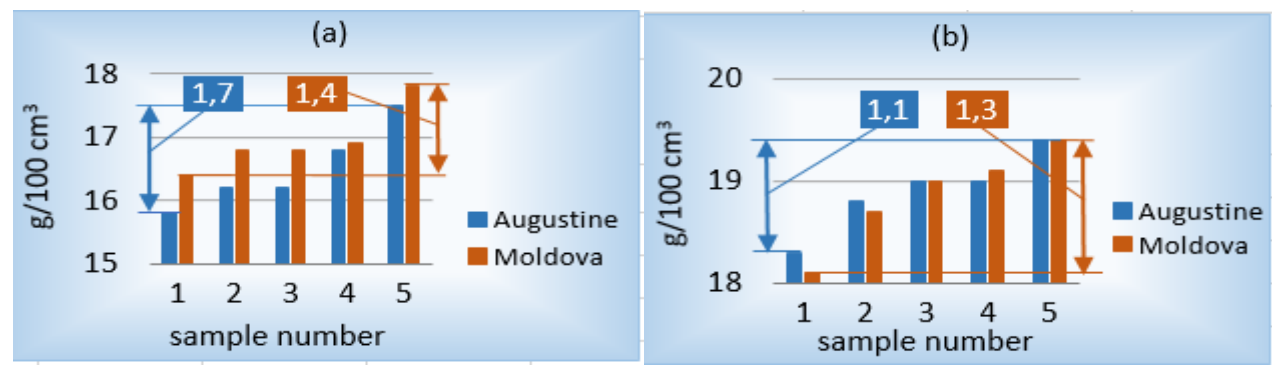

Fig. 3. The reaction norm of the sugar content of grape juice to natural conditions without the application of fertilizers (a) and against the background of the application of fertilizers (b) 


\section{Conclusion}

The reaction norm of table grape varieties Augustine and Moldova in unstable weather conditions of the moderate continental climate of the south of Russia has been established. In the Augustine variety, the lower limit of the modification variability of the cluster mass is $354 \mathrm{~g}$ and the upper limit is $410 \mathrm{~g}$, the grape yield is $8.1 \mathrm{~kg} / \mathrm{bush}$ and $11.5 \mathrm{~kg} / \mathrm{bush}$, the sugar content of grape juice is $15.8 \mathrm{~g} / 100 \mathrm{~cm}^{3}$ and $17.5 \mathrm{~g} / 100 \mathrm{~cm}^{3}$, in the Moldova variety, respectively, 387 and $457 \mathrm{~g}, 9.6$ and $13.2 \mathrm{~kg} / \mathrm{bush}$, the sugar content of grape juice is 16.4 $\mathrm{g} / 100 \mathrm{~cm}^{3}$ and $17.8 \mathrm{~g} / 100 \mathrm{~cm}^{3}$. Against the background of the application of fertilizers in the Augustine variety, the lower limit of the modification variability of the cluster mass is $424 \mathrm{~g}$, the upper limit is $482 \mathrm{~g}$, the grape yield is $10.6 \mathrm{~kg} / \mathrm{bush}$ and $17.9 \mathrm{~kg} / \mathrm{bush}$, the sugar content of grape juice is $18.38 \mathrm{~g} / 100 \mathrm{~cm}^{3}$ and $19.48 \mathrm{~g} / 100 \mathrm{~cm}^{3}$, in the Moldova variety, respectively, $421 \mathrm{~g}$ and $498 \mathrm{~g}, 11.9 \mathrm{~kg} / \mathrm{bush}$ and $18.1 \mathrm{~kg} / \mathrm{bush}$, the sugar content of grape juice is 18.1 $\mathrm{g} / 100 \mathrm{~cm}^{3}$ and $19.4 \mathrm{~g} / 100 \mathrm{~cm}^{3}$. The reaction norm of the Augustine grape variety according to the phenotypic traits is following: the cluster mass is $56 \mathrm{~g}$, the grape yield is $3.4 \mathrm{~kg} / \mathrm{bush}$ and the sugar content of the berry juice is $1.7 \mathrm{~g} / 100 \mathrm{~cm}^{3}$, of the Moldova variety is $70 \mathrm{~g}, 3.6$ $\mathrm{kg} /$ bush and $1.4 \mathrm{~g} / 100 \mathrm{~cm}^{3}$, respectively. Against the background of the application of fertilizers, the reaction norm of phenotypic traits of the Augustine grape variety is following: the mass of the bunch is $58 \mathrm{~g}$, the grape yield is $7.3 \mathrm{~kg} / \mathrm{bush}$ and the sugar content of the berry juice is $1.1 \mathrm{~g} / 100 \mathrm{~cm}^{3}$, for the Moldova variety, respectively, $77,6.2$ and $1.3 \mathrm{~g} / 100 \mathrm{~cm}^{3}$.

\section{References}

1. G.M. Bucur, L. Dejeu, Bull. Univ. Agr. Sci. and Vet. Met., Cluj-Napoca. Ser. Hort., 71(2), 339-340 (2014) http://dx.doi.org/10.15835/buasvmen-hort:10402

2. G. Brunetto, G.W.B. De Melo, M. Toselli, M. Quartieri, M. Tagliavini, Rev. Bras. Frutic., 37 (4), (2015) https://doi.org/10.1590/0100-2945-103/15

3. C. Perin, A. Fait, F. Palumbo, M. Lucchin, A. Vannozzi, Front. Plant Sci., 11, 822 (2020) http://doi.org/10.3389/fpls.2020.00822

4. T. Popovic, S. Mijovic, D. Raicevic, R. Pajovic, Agricult. Forest., 62(2), 275-282 (2016) http://dx.doi.org/10.17707/AgricultForest.62.2.24

5. M. Boselli, G. Tempesta, M. Fiorilo, M. Brandi, BIO Web Conf., 7, 01012 (2016) https://doi.org/10.1051/bioconf/20160701012

6. D.E. Russo, A.A. Krasilnikov, O.N. Sheludko, Fruit growing and viticulture of South Russia, 67(1), 261-282 (2021) http://doi.org/10.30679/2219-5335-2021-1-67-261-282

7. G. Gavrilescu, B. Bois, BIO Web Conf., 7, 01013 (2016) https://doi.org/10.1051/bioconf/20160701013

8. V.S. Petrov, A.E. Mishko, M.A. Sundyreva, D.M. Tsiku, A.A. Marmorshtein, Magarach. $\begin{array}{llll}\text { Viticulture and } \quad \text { Winemaking, } & \text { 23(1), } & 15-20 & \text { (2021) }\end{array}$ http://doi.org/10.35547/IM.2021.22.94.002

9. Sh.N. Guseinov, S.V. Mayborodin, IOP Conf. Ser.: Earth Environ., 624, 012055 (2021) http://doi.org/10.1088/1755-1315/624/1/012055

10. D.B. Terry, S.K. Kurtural, Am. J. Enol. Vitic., 62 (4), 426-437 (2011) http://doi.org/10.5344/ajev.2011.11022

11. N. Pavlyuchenko, N. Zimina, S. Melnikova, O. Kolesnikova, E3S Web Conf., 210, 05011 (2020) https://doi.org/10.1051/e3sconf/202021005011

12. M-L. Lung, N. Pop, F. Ciobanu, A. Babes, C. Bunea, S.-L. Lazar, Bul. Univ. Agr. Sci. and Vet. Med. Cluj-Napoca. Hort., 69 (1), 219-227 (2012) 
https://www.researchgate.net/publication/289534096_Environmental_Factors_Influence on_Quality_of_Wine_Grape_Varieties_in_Four_Different_Areas_of_Culture

13. A. Marmorshtein, V. Petrov, A. Lukyanov, A. Lukyanova, A. Kovalenko, E3S Web Conf., 254, 02026 (2021) http://doi.org/10.1051/e3sconf/202125402026

14. K. Koyama, H. Ikeda, P.R. Poudel, N. Goto-Yamamoto, Phytochem., 78, 54-64 (2012) http://doi.org/10.1016/j.phytochem.2012.02.026

15. F. Martinez Toda, P. Balda, Vitis, 53(1), 17-20 (2014) https://doi.org/10.5073/vitis.2014.53.17-20

16. M. Niculcea, L. Martinez-Lapuente, Z. Guadalupe, M. Sanchez-Diaz, B. Ayestarán, M. C. Antolín, Vitis, 54(1), 9-16 (2015) https://doi.org/10.5073/vitis.2015.54.9-16

17. N. Mohammadkhani, R. Heidari, N. Abbaspour, Vitis, 52(3), 105-110 (2013) https://doi.org/10.5073/vitis.2013.52.105-110 